\title{
МЕТОДЫ ДИПЛОМАТИИ ПЕРИОДА ЧЖАНЬГО: СТРАТЕГИЯ ЧЖАН И
}

\section{DIPLOMACY METHODS OF ZHANGUO PERIOD: ZHANG YI}

N. Bogdanova

Summary: The article is devoted to the development of diplomacy in ancient China during the Zhanguo period (戰國). This is the time of the transition from the feudal system to a more progressive one. Seven strongest kingdoms (Wei, Han, Qi, Qin, Zhao, Chu, Yan) are fighting for leadership. For a complete victory in the creation of a unified empire, the Qin ruler had to, if possible, peacefully subjugate the remaining 6 kingdoms, using cunning diplomatic techniques. It was then that the attitude towards the ambassador changed, now he is not only the "voice" of the ruler, but also his adviser in diplomatic matters. Using the example of the strategist Zhang $\mathrm{Yi}$, the role of a diplomat in the Zhanguo era is examined. Purpose of the study. Analyze the methods of strategy of the famous diplomat of antiquity Zhang Yi, who became the founder of the union 连 «(" lianheng "). According to Sima Qian's records, Zhang Yi proposed to unite the six kingdoms around the powerful Qin kingdom in a "horizontal union." Show by examples what strategies Zhang Yi used to embroil neighbors and induce them to act in the interests of the Qin state. Materials and methods. In their work, the authors rely on sources and literature in Chinese, as well as research materials in Russian, Chinese and English. Based on Chinese sources, as well as using a wide range of literature, primarily from Chinese researchers, the authors show the tactics of fighting, which is characteristic of Chinese strategic thinking, based on traditional philosophy. Conclusions. The authors note the growing role of the personality of the ambassador, the diplomat of the Zhanguo period. The article analyzes Zhang Yi's diplomatic activities through his application of strategies. Zhang Yi used the "method of persuasion" "势 禁 法" "shi jin fa" ("way to keep by force"), with which he managed to unite the scattered principalities into an alliance with the powerful kingdom of Qin. As a result, a centralized state was formed. Zhang Yi's methods of conducting diplomatic work played a significant role in the further history of China.

Keywords: history, diplomacy, history of China, history of diplomatic relations, Zhang Yi, foreign policy.

\author{
Богданова Надежда Андреевна \\ К.и.н., ст. преподаватель, Российский университет \\ дружбы народов (г. Москва) \\ nad973@yandex.ru \\ Солниева Елена Георгиевна \\ К.филол.н., доцент, Российский университет дружбы \\ народов (2. Москва) \\ solntseva-elena@yandex.ru
}

Аннотация: Введение. Статья посвящена развитию дипломатии древнего Китая в период Чжаньго (戰國). Это время перехода от феодального строя к более прогрессивному. За лидерство борются семь сильнейших царств (Вэй, Хань, Ци, Цинь, Чжао, Чу, Янь). Для полной победы в создании единой империи правителю Цинь необходимо было, по возможности, мирным путем подчинить себе остальные 6 царств, используя хитрые дипломатические приемы. Именно тогда и меняется отношение к послу, теперь он не только «голос» правителя, но и его советник в дипломатических вопросах. На примере стратега Чжан И рассматривается роль дипломата в эпоху Чжаньго. Цель исследования. Проанализировать методы стратегии известного дипломата древности Чжан И, ставшего основателем союза 连横 («ляньхэн»). Согласно записям Сыма Цяня, Чжан И предложил объединить шесть царств вокруг сильного царства Цинь В «союз по горизонтали». Показать на примерах, какие стратегии применял Чжан И, чтобы рассорить соседей и побудить их действовать в интересах государства Цинь. Материалы и методы. В своей работе авторы опираются на источники и литературу на китайском языке, а также материалы научных исследований на русском, китайском и английском языках. Основываясь на китайских источниках, а также, используя широкий круг литературы, прежде всего, китайских исследователей, авторами показана, характерная для китайского стратегического мышления, тактика ведения борьбы, основанная на традиционной философии. Выводы. Авторами отмечается возрастающая роль личности посла, дипломата периода Чжаньго. В статье произведен анализ дипломатической деятельности Чжан И через применение им стратегий. Чжан И использовал «метод убеждения» 《势禁法》 《ши цзинь фа» («способ держать силой»), с помощью которого ему удалось объединить разрозненные княжества в союз с сильным царством Цинь. В результате было образовано централизованное государство. Методы ведения дипломатической работы Чжан И сыграли немалую роль В дальнейшей истории Китая.

Ключевые слова: древний Китай; дипломатия; стратегия; история Китая; дипломатические отношения; Чжан И.

Произошел распад государства Цзинь на три части, ставшие позднее княжествами Чжао, Вэй и Хань, которые впоследствии с Ци, Цинь, Чу и Янь составили семь сильнейших царств.

В период Чжаньго управление важнейшими царствами постепенно перешло в руки министров-цинов, потомки некоторых из них стали главами княжеств. Новые 
правители стремились к новой системе управления, их роль росла, управление государством было уже сосредоточено в руках того, кто находился у власти. В конце IV в. до н.э., как пишет известный востоковед Л.С. Васильев, большинство правителей уже называли себя ванами (ранее этот титул носил чжоуский сын Неба и самовольно чуские правители) [Васильев 2006: 87]. На смену классу аристократии приходят ши, ученые мужи, не имевшие знатного происхождения. Ученые ши, являясь странствующими мыслителями и стратегами, часто поступали на службу к вану одного или нескольких царств и в этом случае получали должность сяна. Сян являлся не только советником вана, но и выполнял дипломатические функции в общении с правителями других государств.

В период «Воюющих царств» «представители разных философских школ становились советниками правящей элиты, предлагая правителям свои идеи государственного реформирования, а также свои варианты тактики ведения войны» [Богданова 2015: 121]. Наиболее известными советниками того периода, согласно мнению российских и китайских исследователей, были Су Цинь и Чжан И, основатели двух противоборствующих направлений: «союз по вертикали» и «союз по горизонтали».

Среди произведений времен Чжаньго особое место занимает книга «Искусство войны» великого стратега Сунь-цзы. Работы Конфуция и Сунь-цзы серьезно повлияли на стратегическое мышление китайцев.

Чжаньго - эпоха создания основных политических институтов, которые определяли государственную систему в Китае. Это время формирования различных школ мысли. Существовало два ведущих направления: «конфуцианцы» и «законники» (или «идеалисты» и «реалисты») [Чу Шулун, Цзинь Вэй 2008]. «Конфуцианцы» стремились применять гуманные методы для решения конфликтов, «законники» же, в свою очередь, предлагали опираться на собственные силы, хитрость, тактику [Чу Шулун, Цзинь Вэй 2008: 5-7].

В статье в качестве источников были привлечены такие памятники как «Исторические записки» Сыма Цяня [Сыма Цянь, 6, 7 2014], «Планы сражающихся царств» [Мяо Вэньюань, Мяо Вэй, Ло Юнлянь 2012] , «Тридцать шесть стратагем и искусство ведения войны Сунь-цзы» [Сунь-цзы 2000], «Чжуан-цзы» [Перевод Малявина В.В. 1985] и др. на китайском, английском и русском языках. Авторами были изучены работы выдающихся исследователей истории древнего Китая, в частности труды и переводы Р.В. Вяткина, К.В. Васильева, Л.С. Васильева, В.В. Малявина, Л.Д. Позднеевой и др.

\section{Союзы «Хэчзун» и «^яньХэн»}

Как только речь заходит о таких выдающихся личностях как Су Цинь и Чжан И, сразу же стоит упомянуть стратегии «хэцзун» 合纵и «ляньхэн» 连横. Су Цинь - представитель «союза по вертикали» «Хэцзун», цель которого заключалась в объединении 6-ти государств с севера на юг против набирающего мощь Цинь. Чжан И - представитель «союза по горизонтали» «ляньхэн» 连横. Главная задача этого направления - помочь княжеству Цинь создать могущественное государство, объединившись В союз с запада на восток, подчинив себе остальные княжества.

Появление дипломатических стратегий Су Циня и Чжан И в период «Сражающихся царств» имело свои предпосылки. Понятия «раскол» и «воссоединение» взаимно влияют друг на друга. Китайский исследователь Юн Жунбо, подчеркивая, что «объединение» нельзя отделить от «раскола», провел параллель с фразеологизмом «分久必合, 合久必分》, что означает «давно разделившийся должен воссоединиться, давно воссоединившийся должен разделиться» (подразумевается, что длительно разобщенное должно объединиться, а длительно объединенное непременно распадется) [Юн Жунбо 2017: 155-183]. Ученый подводит нас к тому, что ситуация с противостоянием двух направлений возникла не случайно. После эпохи правления Чжоу наступил раскол, период смуты, борьба за влияние и власть. В сложившейся ситуации встал вопрос об управлении государством, стали появляться философские школы и учения об управлении страной. Возникли две дипломатические линии, две политики, одна из которых была направлена на раскол, а другая напротив - на слияние. Опыт союзов «по вертикали» и «по горизонтали» показал, что в мире не существует «неизменной» или «единственной» политической стратегии, так же как и не существует единой модели управления государством.

Согласно записям Сыма Цяня, в 334 г. до н. э. политик Су Цинь, видя растущую силу царства Цинь, выдвинул идею сплотиться против сильнейшего и создать коалицию с севера на юг. Дипломатия Цинь, в противовес союзу «хэцзун» 合纵, а также «...выражая готовность заключить соглашение с любым их восточных княжеств и тем разрушить единый фронт врагов», предложила объединиться в союз с запада на восток «ляньхэн» 连横 [Вяткин, 1 2001: 341. Коммент. 249].

Философ Хан Фэй-цзы дал следующую характеристику союзам: «Вертикальный союз - это союз многих слабых для нападения на одного сильного, а горизонтальный союз - это служение одному сильному для нападения на других слабых» [Цит. по Вяткин, 1 2001: 341. Коммент. 249]. 
Выступления представителей дипломатических школ «хэцзун» и «ляньхэн» перед ванами шести царств построены по одному сходному принципу, только там, где Су Цинь гарантирует успех, Чжан И подчеркивает просчеты и недостатки [Васильев 1968: 56]. В «Исторических записках» и некоторых главах «Планов сражающихся царств» подробно изложены обращения обоих политиков к правителям княжеств. Несмотря на предположение о вымышленности некоторых речей Су Циня и Чжан И, большинство историков сходятся во мнении, что изворотливость и хитрость являлись главным оружием дипломатов Чжаньго.

\section{Чжан И (张仪). Союз «по горизонтали»

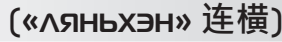

Знаменитый дипломат и стратег периода Чжаньго (战国V - III вв. до н. э.), Чжан И родился в государстве Вэй. В ранние годы Чжан И, как и его оппонент Су Цинь, учился у Гуй Гу-цзы, постигая науку переговоров и стратегии. Так же, как и Су Цинь, являлся странствующим ши и стремился занять пост сяна при дворе одного из шести сильных государств.

Чжан И был принят ваном могущественного государства Цинь, который предложил ему пост советника (сяна), если Чжан И выполнит его приказ. Повеление государя заключалось в том, чтобы уговорить правителей шести княжеств (Чу, Ци, Янь, Чжао, Вэй, Хань) выйти из союза «хэцзун» 合纵, созданного его оппонентом Су Цинем. Планом Чжан И было убедить царства объединиться в новый союз «ляньхэн» 连横, центром которого должно было стать сильное государство Цинь.

В «Планах сражающихся царств» сохранился текст, объясняющий причину, по которой именно Чжан И был отправлен в царства союза «хэцзун»合纵. Согласно древнему памятнику, циньский Хуай-ван сказал Хань Цюань-цзы: «Су Цинь обманул (оскорбил) меня, он хочет воспользоваться своей хитростью и изменить позиции правителей [царств] Дуншань, тем самым обмануть (оскорбить) Цинь...» (《秦惠王谓寒泉子曰: 苏秦欺 寡人, 欲以一人之智反覆东山之君, 从以欺秦») Цинь [Мяо Вэньюань, Мяо Вэй, Ло Юнлянь 2012: 71-72]. Далее Хуай-ван продолжил, что он давно уже недоволен Су Цинем и настроен против его действий по объединению царств в единый союз. Он сказал, что планирует отправить посла в царства, которые обошел Су Цинь и сказать местным правителям, что объединение невозможно. Хань Цюань-цзы ответил Хуай-вану: «Прошу одобрить назначение заезжего сановника Чжан И послом к другим правителям» (《善我国家使诸侯, 请使客卿张仪》). Так, Чжан И уже в качестве представителя Цинь отправился в царства, где уже побывал Су Цинь [Мяо Вэньюань, Мяо Вэй, Ло Юнлянь 2012: 71-72]. Только в случае Чжан И его речи, обращенные к правителям царств Вэй, Чу, Хань, Ци, Янь и Чжао были противоположны речам Су Циня и направлены на создание «союза по горизонтали».

Некоторыми исследователями предполагается недостоверность речей Чжан И, как, впрочем, и высказываний Су Циня. Необходимо отметить, что это лишь одна из версий происходивших в древности событий, поскольку историки указывают на противоречия и несовпадения в текстах источников тех лет. Так, К.В. Васильев, анализируя записи «Чжаньго-цэ» отмечает, что эпизод, приведенный выше, относят к комплексу вымышленных речей дипломатов Су Циня и Чжан И [Васильев 1968: 100]. Существуют расхождения во временных рамках, поскольку Уаньцзы Ци, который, согласно источникам, являлся вторым претендентом на должность представителя от Цинь, получил титул Уань-цзюн в 278 г. до н. э. [Мяо Вэньюань, Мяо Вэй, Ло Юнлянь 2012: 71-72]. Однако выдающийся исследователь К.В. Васильев полагает, что «эпизод с дипломатическим агентом Цинь скорее относится к 20-м годам IV в. до н. э.» [Васильев 1968: 100]. Ссылаясь на мнение китайского историка Цы Сы-хэ, ученый отмечает, что речи дипломатов, приведенные в «Планах Сражающихся царств» зачастую имеют отношение к событиям, случившимся после смерти Су Циня и Чжан И. Одна из версий - рассуждения стратегов были характерны для странствующих ученых того времени, сочинителей школы «Цзунхэн» [Васильев 1968: 105].

\section{Особенности стратегии Чжан И. Тактика «четырех шагов»}

По мнению китайского историка Чжоу Гочжу, метод убеждения Чжан И можно назвать - «势禁法》 «ши цзинь фа» («способ держать силой») [Чжоу Гочжу. 2006: 121]. Ученый выделил 4 основных шага в дипломатической стратегии Чжан И, назвав их звеньями.

Первое звено стратега - это тактика «危言䇯听》 «вэй янь сун тин» («говорить об опасностях, пугать слушающего»). Основная цель стратегии - запугать смелыми речами, показать недостатки противника, сообщить ему «ты не справишься», в основе метода давление, демонстрация силы и могущества. Чжан И убеждал вэйского вана: «Земли Вэй простираются менее чем на тысячу ли, [численность войск] не достигает и триста тысяч солдат. Земли вокруг равнинные. Чжухоу могут прийти со всех сторон. Вас не смогут защитить ни выдающиеся горы, ни большие реки» (《魏地方不至千里, 卒不过三十万, 地四 平。诸侯四通辐辏, 无名山大川之限》)。Чжан И настаивал на установлении близких отношений с Чу, Ци, Чжао и Хань.: «Если не объединитесь с Ци, то Ци нападет на востоке; если не наладите дружбу с Чжао, то царство Чжао будет наступать с севера; не объединившись с Хань, получаете угрозу с западной стороны; не сблизившись с Чу, 
Вам грозит нападение с юга» (“不与齐, 则齐攻其东; 不 与赵则赵攻其北; 不合与韩则韩攻其西; 不亲与楚则楚 攻其南“). «Это, так называемый, путь, ведущий к краху и разделу». (《此所谓四分五裂 之道也») [Сыма Цянь, 72014 : 2778].

Второй метод дипломата - «穷追不舍》 «цюн чжуй бу шэ» («гнаться, преследовать без остановки»). Здесь можно привести пример многократных убеждений Чжан И, обращенных к вану царства Вэй о недостатках стратегии Су Циня. Цель - разбить иллюзии противника, лишить уверенности. Чжан И, следуя второму шагу стратегии, объяснял вэйскому вану, что в стремлении объединить Поднебесную, царства примыкают к союзу «по вертикали» 合纵, чтобы жить как братья («今纵者一天下, 约为昆 弟»). «У реки Хуань они принесли в жертву белого коня, дали клятву своему союзу» (《刑白马以盟洹水之上, 以相 坚也»), однако, как продолжил Чжан И, «между родными братьями также может возникнуть борьба за деньги и богатства» (《而亲昆弟同父母, 尚有争钱财》). Поэтому, если вэйский ван пожелает воспользоваться замыслами Су Циня, основанными на лжи и обмане («而欲特怍伪反 复苏秦之余谋》), то «совершенно ясно, что успеха не случится» (《其不可成亦明矣») [Сыма Цянь, 7 2014: 2778] .

Другой пример стратегии «преследования без остановки» можно взять из беседы Чжан И с чжаоским ваном. Снова применив хитрость и убеждение, дипломат указал правителю Чжао на то, что Чу и Цинь породнились, княжества Хань и Лян стали подданными Цинь, царство Ци отдало Цинь земли, богатые рыбой и солью, что для Чжао, по словам Чжан И, «подобно тому, как лишить Чжао правой руки» (《此断赵之右臂也») [Сыма Цянь, 7 2014: 2789].

Третьим шагом для достижения цели Чжан И, по мнению Чжоу Гочжу, стала стратегия «落井下石》 《ло цзин ся ши», смысл которой «бросать камни в человека, упавшего в колодец», бросать камни вслед упавшему в колодец, образное значение: «добивать лежачего». Так, в беседе с вэйским ваном Чжан И, произнеся длинную речь о недостатках Су Циня и его дипломатии, продолжил убеждать правителя подчиниться Цинь, поскольку в противном случае, Цинь нападет на Хэвай, захватит Цзюань, Янь, «другое» Янь ${ }^{1}$, Суаньцзао, разобьет Вэй, поработит Янцзинь. В результате связь Чжао с югом будет отрезана, следовательно прервутся контакты Лян с севером. Далее связи между царствами «хэцзун» будут разорваны, а это грозит Вэй опасностью... (《大王不事秦, 秦下兵攻 河外, 据卷、衍、燕、酸霖, 劫卫取阳晋, 则赵不南, 赵不南而梁不北, 梁不北则 从道绝, 从道绝则大王之国 欲册危不可得也...此臣之所为大王患也»] [Сыма Цянь, 7

\section{4: 2778]}

Применив стратегию «落井下石》 《ло цзин ся ши», Чжан И угрожал чжаоскому вану тем, что Цинь объединит четыре княжества в союз, разобьет Чжао и разделит его земли между ними («约四国为一以攻赵, 赵服, 必四 分其地»)[Сыма Цянь, 7 2014: 2790]. Чжан И говорил оппонентам, что, если они не подчинятся Цинь, то их ждут большие неприятности.

Заключительное звено стратегии «给出路》 «гэй чулу» («дать возможность выхода из ситуации») - предложить решение проблемы, предоставить возможность проанализировать собственную выгоду от сложившейся ситуации, а также понять ущерб в результате невыполнения предложенного «выхода из ситуации». Например, лучший метод, тактика для вэйского вана - это служить Цинь («为大王计, 莫如事秦»). Если Вэй выберет предложенное решение, то нет сомнения в том, что царства Чу и Хань не осмелятся предпринять какие-либо действия против (《事秦则楚、韩必不敢动》). Однако, если Великий ван не прислушается в данный момент к советам Чжан И, то в дальнейшем это грозит потерей возможности присоединиться к союзу Цинь, даже, если вэйский ван изменит намерения (《大王若不听臣...虽欲事秦, 不可得矣》) [Сыма Цянь, 7 2014: 2779].

Чтобы убедить царства в ненадежности «вертикальной политики» Су Циня, Чжан И практически всегда использовал одни и те же дипломатические приемы. Стратег настаивал на том, что вертикальный союз фактически распался и намерение его лидера заключается в том, чтобы еще больше разрушить доверие государств друг к другу. Методы убеждения Чжан И заключаются в основном в том, чтобы подчеркнуть недостатки оппонента (《危言䇯听》 «вэй янь сун тин»), далее преследовать с помощью дипломатического приема 《穷追不舍》 《цюн чжуй бу шэ», затем воспользоваться стратегией «落井 下石» «ло цзин ся ши», чтобы в итоге, применив тактику 《给出路》 «гэй чулу», предложить решение, вынудить подчиниться.

\section{ЗакАючение}

Начиная с Чуньцю и Чжаньго, дипломатические отношения между царствами стали строиться на основе военной дипломатии и тактики ведения войн. Военная сила становится ключевой, за счет ее применения государства расширяют влияние и границы своих владений. В этот период Чжан И уговорил царство Цинь действовать не насилием, а хитростью, решать проблемы с помощью дипломатических приемов. Чжан И, оказавшийся

1 «Другое» Янь, царство к северу от Даляна. Согласно комментариям исследователя Вяткина Р.В., в ранних списках «Исторических записок» не встречается, но упоминается в «Планах Сражающихся царств» [Вяткин, 7. Коммент. 17 к главе 70. 1996: 342]. 
дальновидным стратегом, предложил новый путь решения конфликтов между государствами, а именно путем применения стратагем и стратегий. Известный факт, что китайцы даже в случае угрозы безопасности, в первую очередь, выбирают переговоры вместо применения силы, однако это не означает, что представители этой нации не могут или не желают сопротивляться. В случае необходимости, «китайцы будут бороться так же мужественно, как и все, чтобы защитить свою территорию и национальную гордость» [Богданова 2015: 121].

Таким образом, Чжан И - видный политический деятель своей эпохи, преданно служил Цинь. Продвигая идею «не насилия», дипломат внес вклад в историю китайской дипломатии. Умелая тактика стратега, а также искусная неторопливая политика правителей Цинь значительно повлияли на дальнейший ход истории древнего Китая.

\section{ЛИТЕРАТУРА}

1. Вяткин Р.В. Сыма Цянь Исторические записки («Ши цзи») Пер. с кит., предисл. и коммент. Вяткина Р.В. - Москва: Наука, Т. 7. - 1996. 462 с.

2. Малявин В.В. Чжуан - цзы Пер. с кит. В.В. Малявина - Москва: Наука: 1985.309 с.

3. Монастырев Н.И. Конфуциева летопись «Чуньцю» («Весны и осени») Пер. и примеч. Н.И. Монастырева. Исслед. Д.В. Деопика и А.М. Карапетьянца Москва: Восточная литература РАН. 1999. 351с.

4. Мяо Вэньюань, Мяо Вэй, Ло Юнлянь Планы сражающихся царств. Т. 1. Пекин: Издательство Китай. 2012.526 с.

5. Сыма Цянь Ши цзи Су Цинь лечжуань — Жизнеописание Су Циня [электронный ресурс] // URL: http://www.zanghaihua.org/shiji/464.html (дата oбpaщения 08.08.20).

6. Сыма Цянь Ши цзи Циши Чжан И лечжуань — Жизнеописание Чжан И [электронный ресурc] // URL :http://www.zanghaihua.org/shiji/466.html (дата обращения 08.08.20).

7. Сыма Цянь. Исторические записки. Т. 7. Пекин. 2014. 364 с.

8. Сыма Цянь. Исторические записки. Т. 6. Пекин. 2014. 414 с.

9. Сунь-цзы. Тридцать шесть стратагем и искусство ведения войны Сунь-цзы. Синьцзян. 2000. 247 с.

10. Чжуан-цзы [электронный ресурс] // URL: https://www.gushiwen.org/guwen/zhuangzi.aspx (дата обращения 09.08.20) .

11. Crump J. I. Chan- Kuo Ts'e - Oxford: Clarendon Press. 1970.624 p.

12. Богданова Н.А. К вопросу о роли стратагем в дипломатии Китая// Вестник РУдН. Серия международные отношения. Т. 15. №1. 2015. С. 117 - 124.

13. Васильев К.В. Планы сражающихся царств («Чжань го цэ»). Исследование и переводы - Москва. 1968. 257 с.

14. Васильев Л.С. Древний Китай. Том 3. Период Чжаньго (V - III вВ. до н. э.) - Москва: Университетская книга. 2015. - 680 c.

15. Позднеева Л.Д. Поучение дипломату в Древнем Китае. // Л.Д. Позднеева. // Историко - филологические исследования: сборник статей к 75 - летию академика Н.И. Конрада - Москва: Наука. 1967. 511 с.

16. История сегодня. Этот день в истории. Гуй Гу-цзы - основоположник школы «Цзунхэн цзя» [электронный ресурс] // URL: http://www.todayonhistory.com/ people/201909/36265.html (дата обращения: 18.09.2020).

17. Зенгер Х. фон. Стратагемы. 0 китайском искусстве жить и выживать. Т. 1, 2. - М.: Эксм0. 512 с., 1024 с.

18. Чжан И Лишишан дэ цзиньтянь. История сегодня. Чжан И [электронный ресурс] // URL: http://www.todayonhistory.com/people/201506/9637.html (дата обращения: 19.02.2021).

19. Чжоу Гочжу 2006 Искусство убеждения Су Циня и Чжан И. Сравнительное исследование. // Шаньдунского института кадрового управления молодежи 2006. № 5. С. 120 - 122.

20. У Тин, Бинь Гао Цюнь 0 стратегии союзя «ляньхэн» в период Чжаньго. На примере того, как представитель «ляньхэн» Чжан И обманул Чу. // Исторические и литературные исследования. Нанкин. 2015. С. $134-140$.

21. Чу Шулун, Цзинь Вэй Дипломатическая стратегия и политика Китая Пекин - 2008. 495 с.

22. Юн Жунбо. Роль политики «союзов хэцзун и ляньхэн» Су Циня и Чжан И // Теория социальных наук. Чанша. 2017 Вып. 19. С. 155 - 183.

23. Bogdanova 2015 - Bogdanova N.A. The roles of Stratagems in China's diplomacy - The Diplomat Magazine. Border crossing. Vol. 1. Issue 6. Pp. 10 - 12 - [электронный ресурс] // URL: https://issuu.com/diploflying/docs/border.crossing.volume1.issue6__ (дата обращения: 23.03.2021). 